\title{
Positive Psychological Capital and Self-Directed Learning Predicting Job Performance in Physiotherapists.
}

\author{
Waranyoo Ongsara ${ }^{a}$, Nontirat Pathanapakdee ${ }^{b}$ \\ ${ }^{a}$ M.A. Candidate in Industrial and Organizational Psychology, Department of Humanities, Faculty of Applied Arts, King \\ Mongkut's Institute of Technology North Bangkok, Bangkok 10800, Thailand, Waranyoo.ptmu@gmail.com \\ ${ }^{\mathrm{b}}$ Department of Humanities, Faculty of Applied Arts, King Mongkut's Institute of Technology North Bangkok, Bangkok \\ 10800, Thailand
}

Article History: Received: 10 November 2020; Revised 12 January 2021 Accepted: 27 January 2021; Published online: 5 April 2021

\begin{abstract}
The objectives of this survey research were 1) to study levels of job performance, positive psychological capital and self-directed learning 2) to study relationship between positive psychological capital and job performance 3) to study relationship between self-directed learning and job performance 4) to predict job performance by positive psychological capital and self-directed learning. The instrument was a questionnaire. Corrected item-total correlations of each item was higher than 0.2 and Cronbach's alpha coefficient for job performance, positive psychological capital, and self-directed learning were .825 , .864 , and .869 , respectively. The sample was 391 physiotherapists in Thailand. The statistics used to analyze data were percentages, means, standard deviations, Pearson correlations, Partial Correlation and stepwise multiple regression analysis. The results revealed that: 1) the physiotherapists had a very high level of job performance, a high level of positive psychological capital, and a high level of self-directed learning; 2) there was a statistically significant relationship between positive psychological capital and job performance $(\mathrm{p}<.01) ; 3)$ There was a significant relationship between self-directed learning and job performance $(\mathrm{p}<.01)$; finally, 4$)$ The 4 elements of positive psychological capital -- self-efficacy, hope and optimism and self-directed learning -- self-managing accounted for $67 \%$ of variance in job performance of physiotherapists.
\end{abstract}

Keywords: Positive Psychological Capital, Self-Directed learning, Job Performance, Physiotherapists

\section{Introduction}

According to the current government policy, Thailand is regarded as a hub for international health centre in order to become new engine of growth to drive future economy and push forward its growth ( $\mathrm{S}$-curve). Health business is included in the national policy to lead the country into Thailand 4.0, with the aim to connect business and investment in advanced technology. This can lead to health service management to reduce unequal access to the healthcare system. Consequently, this is in respond to the aged society in the year 2030 (2573 B.E.), in which Thailand senior population will become one-fourth of the whole population (Department of Health Service Support, 2016).

The Physical Therapy Council aims to provide public physical therapy services in the level of professional standard and quality. Moreover, venue, equipment, including system and device are facilitated to lead to the equal access according to human rights principle, harmonizing with trends and the national development strategies. The efficiency development plan on physiotherapists to become specialists and to be world-wide accepted is also encouraged (Physical Therapy Council, 2017).

Job performance, regarding as the tool of physiotherapist management process, has been related to the strategies of physical therapy council. The result helps physiotherapists to become more efficient, also to acknowledge their strength, weakness, ability and potentiality. In addition, it can guide physiotherapists to improve their weakness and develop their strength accurately so they can reach their highest potentiality. Self-job performance is important since people tend to rely on self-evaluation more than being evaluated by others. People will evaluate their own potentiality to improve themselves regularly and to prepare for opportunity in employing knowledge and ability to achieve work goals (Songloed, 2017).

The research also states that positive psychological capital is related to the job performance in a way of motivating work performance and work devotion from employers. They will gain effort to solve problems while working to achieve work goals. This can be said that the positive psychological capital can create positive relationship between individual and organization (Luthan et al., 2007). Additionally, the positive relation on selfefficacy and job performance has been found (Forbes, 2005). Some studies show that there is a direct relation between resilience and job performance. If workers have high resilience, they will be more creative and can easily 
adjust to changes and challenges in working environment variation. (Coutu, 2002), " It is noticed that the theoretical predict can increase or decrease individual internal positive psychological capital which can affect on volumes of job performances." Employee can always create proactive psychological capital for the benefits in improving their efficiency. Therefore, it can be concluded that the positive psychological capital and job performance in relation with the increasing and decreasing of the psychological capital can affect on job performance (Peterson et al., 2011).The research conducted by Ballout (2009) mentioned that the self-efficacy and career determination are related positively and can affect on job performance of employees.

There is a high competition in the current job market due to the demand on efficient workers of employers and workplaces. So, the sole learning from classroom cannot make learners become high-efficient workers. Learners need to indulge lessons from outside classroom. They need to obtain practical practices to become more efficient and to be accepted. Life-long learning, independence learning and multi-knowledge acquiring should be encouraged. Due to the rapid change in the world, the main educational objective should focus on knowledge acquisition skill development. The educated ones should possess not just academic or professional knowledge, but all aspects. The independence learning allows learners to acquire knowledge according to their desire and passion. This idea is in harmony with the nature of humans in the aspect of the desire to become independently selfguiding. (Charoenchim et al.,2012). The Physical Therapy Council is a professional organization that aims to develop physiotherapists to be specialized in functional movement sciences, life-long learning and developing in order to increase better work quality (Physical Therapy Council, 2017).

The research on the impact of self-directed learning on operation level has been scarcely conducted. However, the study on the mentioned topic in the field of lawyer has revealed that self-directed learning has influenced on the working process of individual lawyer (Alonderiene and Suchotina, 2017). The result covers similar regulations and provides in-depth data about the indirect relation between self-directed learning and individual job performance, for instance, the research challenging the positive influence of knowledge sharing effect on individual working process (Henttonen et al., 2016) or the study on the influence of learning journal reflecting the efficiency development on individual and group (Loo and Thorpe, 2002).

There are also some studies in organizational level on this area such as the study of Tippins and Sohi (2003) and Garcia-Morales et al (2012). The study investigates on the impact of self-directed learning on the organization operating process. It has pointed out the positive impact of the self-directed learning to strengthen the operating process of the organization through the mediums; learning variants of the organization and the ability in knowledge management (Ho, 2008). The study of Ho (2011) has stated that the self-directed learning influences on organizational working process though organizational innovations. However, there has no direct investigation on the direct relation between the self-directed learning and job performance. The study of Tseng (2013) presented the study on theory to prove the relation between the self-directed learning and the efficiency of the business entrepreneur.

\section{Method}

\section{Population and Sample}

The population in this study includes the licensed and professional physiotherapists who legally work in the national institutes under the supervision of the government. The researcher conducted the data collection from The Physical Therapy Association of Thailand on $10^{\text {th }}$ of July, 2020. There are 13,405 members and the sample was randomly selected. The sampling group size is adapted by the approach of Krejcie and Morgan (Ritjaroon, 2004). 373 people were calculated numbers of the participants of the study. To prevent research participants from withdrawal, the researcher added 10 percent of participants so the total number became 410 people which was the similar number to the questionnaires. After considering the quality and investigating the completeness of the questionnaire, the obtained questionnaires were 391.

\section{Instrument of research}

Questionnaire was employed as research tool. It was conducted by studying the theoretical frame, literature review and related theory before writing questions about the surveyed data. The questionnaire was divided into 5 parts:

Part 1: This part included 2 items on the criteria of respondent in the form of check list.

Part 2: This part included 5 items on the general information of respondent in the form of check list. The inquiring data covered gender, age, educational background, work experience and work region.

Part 3: This part included 39 items on the job performance in the form of selecting the best statement. Respondent can decide and choose the most suitable answer about idea, feeling and behavior. The content concerned 3 aspects referring from the component of job performance; management, service and academic. 
Part 4: This part included 36 items on the positive psychological capital in the form of selecting the best statement. Respondent can decide and choose the most suitable answer. The content concerned 4 aspects on the component of the positive psychological capital; self-efficacy, hope, optimism and resilience.

Part 5: This part included 34 items on the self-directed learning in the form of selecting the best statement. Respondent can decide and choose the most suitable answer. The content concerned 3 aspects on the component of the self-directed learning; self-managing, self-monitoring and self-modifying.

From part 3 to part 5, the five rating-scale approach was employed. The answer can be interpreted as follows:

$\begin{array}{lll}\text { Level of opinion } & 5 & \text { means strongly agree } \\ \text { Level of opinion } & 4 & \text { means agree } \\ \text { Level of opinion } & 3 & \text { means neutral } \\ \text { Level of opinion } & 2 & \text { means disagree } \\ \text { Level of opinion } & 1 & \text { means strongly disagree }\end{array}$

\section{Development and measurement of instrument}

The questionnaire was tested on content validity by 3 specialists. The specialists investigated and considered the index of item-objective congruence (IOC) of the questionnaire. After that, the total scores were calculated to find the relation between item and definition. Then, the items with IOC over 0.5 were selected (Piyapimonsit, 2005) addition, the suggestions to improve the questionnaire provided by the specialists to be more precise, more suitable and accurate were used to modify the questionnaire.

Later on, discrimination and reliability of the questionnaire were tested. The questionnaire was tried out by 40 non research participants. Then, the obtained data were calculated to find out the corrected item total correlation. The items that got less than 0.2 points were dismissed (Kanchanawasi and Kanchanawasi, 2016).

Next, Cronbach's Alpha Coefficient (Cronbach, 1990) was employed to analyze each aspect of the questionnaire. Some statements were dismissed at this stage to keep the reliability value of the questionnaire at the level of more than 0.7 (Lacobucci and Duhachek, 2003).

Table1: Corrected Item Total Correlationand Cronbach's Alpha Coefficient

\begin{tabular}{|c|c|c|c|c|}
\hline \multicolumn{2}{|c|}{ Questionnaire } & $\begin{array}{c}\text { Corrected Item Total } \\
\text { Correlation }\end{array}$ & $\begin{array}{l}\text { Cronbach's } \\
\text { Coefficient }\end{array}$ & Alpha \\
\hline \multicolumn{2}{|c|}{ Job performance } & & .825 & \\
\hline 1) & Management & $.219-.585$ & .851 & \\
\hline 2) & Service & $.441-.791$ & .935 & \\
\hline 3) & Academic & $.420-.767$ & .879 & \\
\hline \multicolumn{2}{|c|}{ Positive psychological capital } & & .864 & \\
\hline 1) & Self-efficacy & $.571-.801$ & .934 & \\
\hline 2) & Hope & $.662-.803$ & .951 & \\
\hline 3) & Optimism & $.347-.629$ & .890 & \\
\hline 4) & Resilience & $.452-.619$ & .854 & \\
\hline \multicolumn{2}{|c|}{ Self-directed learning } & & .869 & \\
\hline 1) & Self-managing & $.529-.759$ & .946 & \\
\hline 2) & Self-monitoring & $.285-.658$ & .889 & \\
\hline 3) & Self-modifying & $.528-.848$ & .935 & \\
\hline
\end{tabular}


From table 1, corrected item total correlation on each aspect of the questionnaire possessed the score of more than 0.2 and Cronbach's alpha coefficient of the variable and its aspect obtained more than 0.7 . The total job performance has got 0.825 when each aspect of job performance has obtained 0.851-0.935. The positive psychological capital has got the total score of 0.864, when each aspect has got 0.854-0.951. The self-directed in general has got 0.869, when each aspect has got 0.889-0.946.

\section{Gathering information}

The questionnaire was distributed via online platform which is Google Form. The researcher has promoted and asked for cooperation through the public relation of the Physical Therapy Association of Thailand. The online questionnaire has been opened for 1 month before the data collection

\section{Information analysis}

The statistics used in this study were frequency, percentage, means, standard deviation, Pearson correlation SPSS, coefficient of partial correlation and stepwise multiple regression analysis.

\section{Results}

The results from data analysis can be divided into 3 parts:

1. Result from data analysis on personal characteristics showed that the majority of the sample group is female (291 people), calculated into $74.42 \% .165$ participants were in the age group between 31-40 years old, calculated into percentage of 42.20. 318 participants graduated in undergraduate level, calculated into percentage of 81.33. 171 participants possessed work experience between 1-6 years, calculated into percentage of 43.73. 125 participants worked in Middle region, calculated into percentage of 31.97.

2. Result from data analysis on the relation between positive psychological capital and job performance of the physiotherapists and the relation between the self-directed learning and job performance of the physiotherapists have been explained in the following tables.

Table 2: The coefficient of correlation between the positive psychological capital and job performance of the physiotherapists

\begin{tabular}{llll}
\hline Variable & \multicolumn{3}{l}{ Job performance of the physiotherapists } \\
\cline { 2 - 4 } & $\mathbf{r}$ & $\mathbf{r}^{\mathbf{2}} \times \mathbf{1 0 0}$ & Correlation level \\
\hline Self-efficacy aspect & $.45^{* * *}$ & 20.25 & Moderate \\
\hline Hope aspect & $.28^{* *}$ & 7.84 & Low \\
\hline Optimism aspect & -.06 & 0.36 & Low \\
\hline Resilience aspect & .06 & 0.36 & Low \\
\hline The overall positive psychological capital & $.74^{* *}$ & 54.76 & High \\
\hline$* *$ statistically significant level is 01 & & &
\end{tabular}

** statistically significant level is .01.

Table 2 showed that the overall positive psychological capital had correlation to the job performance of the physiotherapists at the statistically significant level of .01, high level $(\mathrm{r}=.74)$ which was calculated into the percentage of 54.76 .

The positive psychological capital in the aspect of self-efficacy had correlation to the job performance of the physiotherapists at the statistically significant level of .01 , moderate level $(r=.45)$ which was calculated into the percentage of 20.25 .

The positive psychological capital in the aspect of hope had correlation to the job performance of the physiotherapists at the statistically significant level of .01, low level $(\mathrm{r}=.28)$ which was calculated into the percentage of 7.84 .

The positive psychological capital in the aspect of optimism had correlation to the job performance of the physiotherapists at the statistically significant level of .01, high level $(\mathrm{r}=-.06)$ which was calculated into the percentage of 0.36 .

The positive psychological capital in the aspect of resilience had correlation to the job performance of the physiotherapists at the statistically significant level of .01, high level $(\mathrm{r}=.06)$ which was calculated into the percentage of 0.36 . 
Table 3: The coefficient of correlation between the self-directed learning and job performance of the physiotherapists

\begin{tabular}{llll}
\hline Variable & \multicolumn{3}{c}{ Job performance of the physiotherapists } \\
\cline { 2 - 4 } & $\mathbf{r}$ & $\mathbf{r}^{\mathbf{2} \times \mathbf{1 0 0}}$ & Correlation level \\
\hline Self-managing & $.38^{* *}$ & 14.44 & Low \\
\hline Self-monitoring & -.06 & 0.36 & Low \\
\hline Self-modifying & $.21^{* *}$ & 4.41 & Low \\
\hline The overall self-directed learning & $.74^{* *}$ & 54.76 & High \\
\hline$* *$ statistically significant level is .01. & &
\end{tabular}

From table 3, the overall self-directed learning had correlation to the job performance of the physiotherapists at the statistically significant level of .01 , high level $(\mathrm{r}=.74)$ which was calculated into the percentage of 54.76.

The self-directed learning in the aspect of self-managing had correlation to the job performance of the physiotherapists at the statistically significant level of .01, low level $(\mathrm{r}=.38)$ which was calculated into the percentage of 14.44 .

The self-directed learning in the aspect of self-monitoring had correlation to the job performance of the physiotherapists at the statistically significant level of .01, low level $(\mathrm{r}=-.06)$ which was calculated into the percentage of 0.36 .

The self-directed learning in the aspect of self-modifying had correlation to the job performance of the physiotherapists at the statistically significant level of .01, low level $(\mathrm{r}=.21)$ which was calculated into the percentage of 4.41 .

3. The equation to predict job performance of the physiotherapists

Table 4:Stepwise multiple regression analysis for selecting positive psychological capital and self-directed learning which can predict job performance of the physiotherapists

\begin{tabular}{|c|c|c|c|c|c|c|c|}
\hline & ve variable & $\mathbf{R}$ & $\mathbf{R}^{2}$ & $\operatorname{Adj} R^{2}$ & $\overline{\mathbf{S E}_{\text {est }}}$ & $\mathbf{F}$ & $\mathbf{p}$ \\
\hline \multicolumn{8}{|c|}{ Constant } \\
\hline- & Self-efficacy & .78 & .61 & .61 & .30 & $600.21^{* *}$ & .00 \\
\hline \multicolumn{8}{|c|}{ Constant } \\
\hline- & Self-efficacy & .81 & .66 & .66 & .28 & $380.19^{* *}$ & .00 \\
\hline- & Self-managing & & & & & & \\
\hline \multicolumn{8}{|c|}{ Constant } \\
\hline- & Self-efficacy & .82 & .67 & .67 & .27 & $260.38^{* *}$ & .00 \\
\hline- & Self-managing & & & & & & \\
\hline- & Hope & & & & & & \\
\hline \multicolumn{8}{|c|}{ Constant } \\
\hline- & Self-efficacy & .82 & .67 & .67 & .27 & $199.05^{* *}$ & .00 \\
\hline- & Self-managing & & & & & & \\
\hline- & Hope & & & & & & \\
\hline- & Optimism & & & & & & \\
\hline
\end{tabular}

Table 4 stated that there are 4 variables which can predict the job performance of the physiotherapists; self-efficacy, self-managing, hope and optimism. The coefficient of correlation of the job performance is .82 . The job performance predict percentage is 67.00 , with the statistically significant level at .01 and error value of .27 . 
Table 5: Equation pattern for the job performance of the physiotherapists

\begin{tabular}{|c|c|c|c|c|c|}
\hline Predictive variable & $\mathbf{b}$ & SE b & $\boldsymbol{\beta}$ & $\mathbf{t}$ & $\mathbf{p}$ \\
\hline Constant & 1.24 & .12 & - & $10.03^{* *}$ & .00 \\
\hline Self-efficacy & .70 & .03 & .78 & $24.50^{* *}$ & .00 \\
\hline Constant & 1.02 & .12 & - & $8.66^{* * *}$ & .00 \\
\hline Self-efficacy & .44 & .04 & .49 & $10.57^{* *}$ & .00 \\
\hline Self-managing & .31 & .04 & .37 & $7.98^{* *}$ & .00 \\
\hline Constant & .96 & .12 & - & $8.05^{* *}$ & .00 \\
\hline - $\quad$ Self-efficacy & .38 & .05 & .42 & $7.98^{* *}$ & .00 \\
\hline Sent-entedey & .25 & .04 & .30 & $5.76^{* *}$ & .00 \\
\hline Self-managing & .14 & .05 & .16 & $2.77 * *$ & .01 \\
\hline Hope & & & & & \\
\hline Constant & 1.03 & .12 & - & $8.43^{* *}$ & .00 \\
\hline - $\quad$ Self-efficacy & .39 & .05 & .43 & $8.22^{* * *}$ & .00 \\
\hline Sent-cintacy & .28 & .05 & .33 & $6.19^{* *}$ & .00 \\
\hline Self-managing & .18 & .05 & .20 & $3.44^{* *}$ & .00 \\
\hline Hope & -.09 & .04 & -.11 & $-2.38^{*}$ & .02 \\
\hline Optimism & & & & & \\
\hline
\end{tabular}

Table 5 showed that the equation pattern for the job performance of the physiotherapists can be created by this formula.

Job performance $=1.03+0.39($ Self-efficacy $)+0.28($ Self-managing $)+0.18($ Hope $)-0.09($ Optimism $)$.

Raw score, then, can be converted into Z-score and obtain the equation in the standard pattern as follows:

Job performance $=0.43($ Self-efficacy $)+0.33$ (Self-managing $)+0.20($ Hope $)-0.11($ Optimism $)$.

\section{Discussion}

The results of the study can be found that:

The positive psychological capital was correlated to the job performance of the physiotherapists in high level of the statistical significance at .01. This was interpreted that the physiotherapists are confident in their performances and have goals for their responsibilities. In addition, they can find methods to help achieve their goals successfully. When confronting difficulties, they can adjust their emotions abruptly in order to continue completing their jobs. The mentioned qualifications can be regarded as the positive psychological capital that help encourage the physiotherapists to perform their jobs better. This relates to the theory proposed by Luthans et al (2007), stating that positive behavior consists of self-efficacy, hope, optimism and resilience. When combining into one variable, it becomes efficient to the job performance. The process of healing patients needs to be delicate and careful. It is possible to confront difficulties from working with patients, including co-working with other professions. It is important to solve the problems as soon as possible in order to achieve work goals. This can be related to the study of Songloed (2017), stating that the ability to motivate acting and to accept mistake can lead to learning, positive perception and self-adjusting to possible obstacles properly. This qualification then leads to behaviors that can be assessed, developed and managed efficiently which at the end can provide quality job performance.

The result also showed that the overall self-efficacy was correlated to the job performance of the physiotherapists in high level with the statistical significance of .01. The physiotherapists have continual learning to develop better healing methods. They show interest in their job by setting learning goal, learning objective, select and prepare to learn about interesting knowledge which can be applied to healing patients. This is related to the research of Guglielmino et al (1987). The research focused on the aptness in self-directed learning and job performance. It was found that the staff with outstanding job performance and high level of creativity possess higher score in the aptness on self-directed learning than others. The people with outstanding job performance also have higher skill in problem solving than others.

The higher educated people often own the aptness in self-directed learning more than others. The research of Charoenchim et al (2012) stated that there is a high competition in the current job market due to the demand on 
efficient workers of employers and workplaces. So, the sole learning from classroom cannot make learners become high-efficient workers. Learners need to indulge lessons from outside classroom. They need to obtain practical practices to become more efficient and to be accepted. Life-long learning, independence learning and multi-knowledge acquiring should be encouraged.

Moreover, the research result has stated that there are 4 variables which can predict the job performance of the physiotherapists; self-efficacy, self-managing, hope and optimism. The coefficient of correlation of the job performance is .82 . The job performance predict percentage is 67.00 , with the statistically significant level at .01 and error value of .27 .

The positive psychological capital in the aspect of self-efficacyis the first variable that can predict the job performance of the physiotherapists. When the physiotherapists are confident that they can heal their patients, they will become confident in applying their knowledge to help the patients. Their confidence will also shine while exchanging curing ideas with other professional workers, including finding other methods to increase job efficiency. When confronting patients with difficulties in healing, the physiotherapists view this as a challenge and will make effort in overcoming the difficulty. This behavior can be related to the theory proposed by Bandura (1986). People with self-efficacy usually put their highest effort and have high motivation in achieving their responsibilities successfully. The research of Wongtone (2011) also states that self-efficacy can radiate confidence in job performance, passion for overcoming difficulties and challenges, including effort in completing work goals.

\section{Self-directed learning aspect}

This aspect comes as the second among the variables influencing on job performance of the physiotherapists. They are determined and have work goals to achieve in order to improve their healing method, including the enthusiasm to search for new knowledge and cure in physiotherapy. Self-directed learning motivates the physiotherapists to do learning plan and to schedule their routine to improve their healing process to become flawless. This, then, provides better outcomes to the patients. The mistake can help the physiotherapists learn. The physiotherapy association has played an important role in promoting self-directed learning and organizing trainings for better healing process. Charoenchim et al (2012) stated in the study that the learning focusing on learner-center can promote self-directed learning and encourage learners to become more creative, unique, decisive and responsible. All mentioned qualities can be applied for better living-condition. Garrison (1997) proposed that self-managing in creating activities for learning objective can create motivation to achieve the goals.

\section{The positive psychological capital}

The third variable is hope. Hope ignites force and motivation in the physiotherapists to achieve their work goals. When being motivated and determined, they will put their best effort to heal the patients. Besides, new ideas or methods will be applied to find out better healing process. Hope will help the physiotherapists to overcome difficulties they may confront when performing duties. Luthan et al (2007) stated that having hope affected on job performance of the staff. Those with high hope usually had objectives to focus on, including motivation in performing and being successful. Difficulties, to them, were seen as challenges to overcome. These people with hope possess the effort to search for methods to achieve their goals. The research of Wongtone (2011) mentioned that hope leads to the confidence in job performing in order to reach the targets.

\section{The positive psychological capital}

Optimism is the fourth variable that has predicted in negative. This may happen due to the believe that the physiotherapists should not cause mistakes, unexpected circumstances or incorrect diagnosis. The physiotherapists should not be positive or romanticize the mistakes while healing since this might cause the life of the patient. This variable is an argument to the study of Luthan et al (2007) which suggested that being optimistic is positive to job performance. The optimistic staff is believed to have work motivation even though confronting obstacles. The motivation can lead to the expectation on positive outcomes in healing and being successful in reaching targets. The study of Songloed (2017) found that being optimistic can influence on patience in work, including the determination and the satisfaction to become a part or to increase the determination in achieving work target.

\section{Suggestion}

\section{Suggestions for applying results of the research}

The positive psychological capital in the aspect of self-efficacy: It can be applied in developing knowledge and proficiency in professional career. The physiotherapists can apply this research result to achieve their work goals and to accept individual proficiency. It is important to have confidence in healing patients, including their colleagues by valuing their job responsibility, viewing obstacles as challenges and solving problems with their best effort. When the physiotherapists accept their job performances, they will learn to try and put effort in their work. This will provide opportunity for their career growth as well. 
The second variable is the self-directed learning. The physiotherapists should have learning determination, knowledge development and eagerness in learning all the time. They should view the job objective and plan to apply obtained knowledge to effectively heal patients. Moreover, it is important to schedule work and learn period properly. Planning in advance can help reach the set goals. The previous mistakes can be lessons for improving physiotherapy process. It is also necessary to discover new knowledge for more effective healing methods by considering about safety and accuracy.

The third variable is hope. The result in this aspect can be applied in terms of creating determination to complete job target, participating in professional performance, being confident in order to have self-motivation. The power of hope will help physiotherapists in overcoming any difficulties and achieving their expected outcomes.

The fourth variable is optimism. This variable drives the physiotherapists to perform their best while working to prevent from any unexpected circumstances or mistakes in diagnosing or healing. The idea of mistake is possible should not exist since the possible mistake might cost the life of the patient. The physiotherapists should have confidence while healing their patients with their best efficiency, including strictly following all regulations and keeping work ethics.

\section{Suggestions for future research}

1. This research is only the assessment of the physiotherapist. It may have error due to the bias or misperception in assessment. Therefore, the future research should include the assessment from the superior or patients who experienced the healing process to obtain more accurate assessment.

2. There should have more questionnaires for different sample groups, such as physiotherapists from public and private organizations, including from other sectors. Having variety of sample groups can acknowledge various perspectives.

3. There should be more research with others variables in order to apply in working and solving problems in various aspects such as variables on job satisfaction or job pleasure.

4. Research and development approach should be employed in the future research for obtaining program training about positive psychological capital. Organizing trainings for the physiotherapist and assessing on the positive psychological capital aspect of the pre- and post- training might help develop the future performance of the physiotherapist.

\section{Conclusion}

The overall positive psychological capital has correlated to the job performance of the physiotherapists at the level of statistical significance at .01 and being considered in high level $(r=.74)$. When considering each aspect, it is found that the self-efficacy is related to the job performance of the physiotherapists at the level of statistical significance at .01 and being considered in neutral level $(r=.45)$. The aspect of hope is related to the job performance of the physiotherapists at the level of statistical significance at .01 and being considered in low level $(\mathrm{r}=.28)$. The aspect of resilience has correlated to the job performance of the physiotherapists, with no statistical significance at .01 and being considered in high level $(\mathrm{r}=.06)$.

The overall self-directed learning has correlated to the job performance of the physiotherapists at the level of statistical significance at .01 and being considered in high level $(\mathrm{r}=.74)$. When considering each aspect, it is found that the self-managing is related to the job performance of the physiotherapists at the level of statistical significance at .01 and being considered in low level $(\mathrm{r}=.38)$. The aspect of self-monitoring is related to the job performance of the physiotherapists, with no statistical significance at .01 and being considered in low level $(r=-$ .06). The aspect of self-modifying has correlated to the job performance of the physiotherapists, with no statistical significance at .01 and being considered in low level $(\mathrm{r}=.21)$.

There are 4 variables which can predict the job performance of the physiotherapists; self-efficacy, selfmanaging, hope and optimism. The analysis has followed the determined hypothesis. The coefficient of correlation in job performance is .82. The job performance predict percentage is 67.00 , with the statistically significant level at .01 and error value of .27. The analysis results on the aspects of self-managing, hope and optimism follow the hypothesis. The coefficient of correlation in job performance is .82 . The job performance predict percentage is 67.00, with the statistically significant level at .01 and error value of .27.

According to the result analysis, the researcher would like to state that though the positive psychological capital and the self-efficacy of the physiotherapists in Thailand are in good level, there are parts that need to be improved when considering in some aspects. The physiotherapists should improve for better self-assessment, selfmodifying and resilience in order to obtain better job performance. 


\section{References}

Alonderiene, R., and Suchotina, N. (2017). "The impact of self-directed learning on work performance of lawyers." Organizations \& Markets in Emerging Economies. Vol.9 No.2.

Ballout, H. I. (2009). “Career commitment and career success: moderating role of self-efficacy.” Career Development International.

Bandura, A. (1986). Social learning theory. Englewood. Cliffs: Prentice-Hall.

Charoenchim Sangduan, et al. (2012). Self-Directed Learning Ability of Pre-Service

Teachers, Faculty of Education and Development Sciences Kasetsart University. Faculty of Education and Development Sciences Kasetsart University.

Costa, A. L. and Kallick, B. (2004). Assessment strategies for self- directed learning. Corwin press. California.

Coutu, D. L. (2002). How resilience works. Harvard business review. Vol.80 No.5 : 46-56.

Cronbach, L. J. (1949). Essentials of psychological testing. (n.p.).

Department of Health Service Support. (2016). Medical Hub Thailand 2017-2026.

Forbes, D. P. (2005). "The effects of strategic decision making on entrepreneurial self- efficacy." Entrepreneurship theory and practice. Vol.29 No.5 : 599-626.

García-Morales, V. J., Jiménez-Barrionuevo, M. M. and Gutiérrez-Gutiérrez, L. (2012). “Transformational leadership influence on organizational performance through organizational learning and innovation.” Journal of business research. Vol.65 No.7 : 1040 - 1050.

Garrison, D.R. (1997). "self-directed learning : Toward a comprehensive model.” Adult Education Quarterly. Vol.48 No.1 : 18-33.

Guglielmino, P. J., Guglielmino, L. M. and Long, H. B. (1987). "Self-directed learning readiness and performance in the workplace." Higher Education. Vol.16 No.3 : 303-317.

Henttonen, K., Kianto, A. and Ritala, P. (2016). "Knowledge sharing and individual work performance: an empirical study of a public sector organization." Journal of Knowledge Management.

Ho, L. A. (2008). "What affects organizational performance?.” Industrial Management and Data Systems.

Ho, L. A. (2011). "Meditation, learning, organizational innovation and performance." Industrial Management \& Data Systems. Vol.111 No.1 : 113-131.

Iacobucci, D. and Duhachek, A. (2003). “Advancing Alpha : Measuring Reliability With Confidence.” Journal of Consumer. Vol.13 No.4 : 478-487

Kanchanawasi Thipsiri and Kanchanawasi Sirichai. (2016). Research Methodology. 1st ed. Bangkok : Chulalongkorn University.

Loo, R. and Thorpe, K. (2002). "Using reflective learning journals to improve individual and team performance.” Team Performance Management: An International Journal.

Luthans, F. et al. (2007). Positive psychological capital : Measurement and relationship with performance and satisfaction. Personnel Psychology. Vol.60 No.3 : 541 - 572.

Peterson, S. J., et al. (2011). "Psychological capital and employee performance: A latent growth modeling approach.” Personnel psychology. Vol.64 No.2 : 427-450.

Phainchuchat Thidanuch. (2015). Factors Affecting Job Performance of Professional Nurses in Hospital under The Jurisdiction of The Ministry of Defense. Master Thesis.

(Nursing Administration), Faculty of Nursing, Burapha University.

Physical Therapy Council. (2017). Physical Therapy Strategic Plan 2017-2026.

Piyapimonsit Chatsiri. (2005). Theory of Testing and Measurement. Faculty of Education, Thaksin University.

Ritjaroon Pichit. (2004). Research Methodology Social Sciences. 2nd ed. Bangkok : House of Kermyst.

Songloed Dolpaphat, Thongkhamrod Renukar and Jeotee Kunchon. (2017). "The Relationship of Positive Psychological Capital and Organization Commitment on Work

Performance of Nursing Faculties, Souther Boromarajonani College of Nursing." Humanities and Social Sciences Journal. Vol.8 No.2 : 27-43.

Tippins, M. J. and Sohi, R. S. (2003). "IT competency and firm performance : is organizational learning a missing link.” Strategic management journal. Vol.24 No.8 : 745- 761.

Tseng, C. C. (2013). "Connecting self-directed learning with entrepreneurial learning to entrepreneurial performance.” International Journal of Entrepreneurial Behavior and Research.

Wongtone Siriporn. (2011). The Relationship between Positive Psychological Capital,

Organization Commitment and Work Performance : A Case Study of a Commercial Bank.

Master Thesis. (Industrial and Organization Psychology), Department of Psychology Faculty of Liberal Arts, Thammasat University. 